\title{
Reflections on the Complexity of Ancient Social Heterarchies: Toward New Models of Social Self-Organization in Pre-Hispanic Colombia
}

\author{
Nathalie Mezza-Garcia \\ Centro de Estudios Políticos e Internacionales, \\ Facultad de Ciencia Política y Gobierno y de Relaciones Internacionales, \\ Universidad del Rosario, Bogotá, Colombia \\ Nathalie.mezza-garcia@urosario.edu.co \\ Tom Froese \\ Instituto de Investigaciones en Matemáticas Aplicadas y en Sistemas, \\ Universidad Nacional Autónoma de México, México; \\ Centro de Ciencias de la Complejidad, \\ Universidad Nacional Autónoma de México, Mexico \\ t.froese@gmail.com \\ Nelson Fernández \\ Laboratorio de Hidroinformática, Facultad de Ciencias Básicas, \\ Universidad de Pamplona, Colombia \\ nfernandez@unipamplona.edu.co
}

\begin{abstract}
All political systems have limitations in their information processing and action capacities to face large-scale crises and challenges, but especially if they happen to be too hierarchically and centrally controlled systems. In contrast, some other cultures whose political structure is heterarchically organized, such as the Zenú, the Muiscas, and the Tayronas in pre-Hispanic Colombia, presented adaptiveness even without advanced scientific knowledge and without powerful centralized top-down control. We therefore propose that creating and analyzing computer models of their decentralized processes of management could provide a broader perspective on the possibilities of self-organized political systems. Our hope is that this approach will eventually go beyond the scope of basic science. It seeks to promote more computermodel-based research of social systems that exhibit an adaptive balance of flexibility and robustness, i.e., systems that do not rely on the current ideal of rule-based control of all systemic aspects, with the practical aim of improving current social and political processes.
\end{abstract}




\section{Introduction}

Being complex, the activity of political systems is determined by the interactions and interdependence of their elements, which partly determine the future of the system. In such a system the isolated study of the components is not sufficient to describe the whole system's dynamics (Gershenson and Fernández, 2012). Its complexity is the result of a balance between creative emergence (adaptivity) and self-organization (stability), and the system's scope for self-determination or autonomy can be estimated by comparing its internal complexity with that of its environment (Fernández, Maldonado, and Gershenson, 2014).

A key management problem is how to address the shortcomings of the classical hierarchical organization of modern institutions. As Mezza-Garcia (in prep.) has argued, the strongly centralized, tree topologies characteristic of our political regimes and their legal decision processes resemble the computational mechanisms of a Turing machine. Political processes are often inflexibly rule-based, encapsulated, sequential, with prespecified halting conditions, centrally coordinated with other processes, and controlled in a top-down manner. In this sense, hierarchical political systems are limited when trying to resolve crises and challenges that threaten the wellbeing of the whole community. Their inherent and irreducible complexity resists current scientific attempts to understand all of the political dynamics in sufficient detail. Moreover, even if we had such perfect knowledge, the inherently nonlinear and noisy interactions between parts of the system and their relation to the environment would thwart political attempts to control them adaptively. Thus, since politics is a nonlinear phenomenon, and the study of sociopolitical dynamics requires space for complexity and nonlinearity, a shift toward the study of heterarchical political systems seems to be a natural tendency when theorizing about political organizations.

The goal of this paper is to present the outlines of a complex systems approach to understanding the organization of past heterarchical societies, in order to highlight their potential computational advantages with regard to the regulation of activities and information processing and their entailments for the organization of human societies. Our hope is that with this kind of computer-based dynamical systems and information theoretical analyses, we will be able to gain valuable knowledge about how it might be possible to improve decision-making processes in our increasingly interconnected and diverse societies. Here we do not understand the concept of computation as being only applicable to processes taking place in a digital Turing machine, but in a general sense as the transformation of information (Gershenson, 2013), and without being limited to the framework of computable logical and mathematical functions (see Eberbach, Goldin, and Wegner, 2004).

In the next section, computational aspects of political systems are briefly presented. Then, in section 3, some relevant insights of complex systems theory are reviewed. 
Section 4 presents three heterarchies of pre-Hispanic Colombia as illustrative examples of complex societies that managed to avoid an overreliance on centralized and top-down elite control. Section 5 briefly discusses a number of open questions and future work.

\section{Computational aspects of political systems and ancient societies}

According to Mezza-Garcia (in prep.), the similarity between a Turing machine and hierarchical political systems can be explained by how the transformation of 'inputs' into decisions in the latter is achieved, namely via sequential routes of rule-based activities that are assumed to take place in a closed manner amongst a selected group of individuals - the government. For those individuals who do not form part of the regime, and even for those who are members of a separate subsection of government, the computation of the decision takes place in a 'black box' until the moment of the 'halt' and the output of a political decision is made available. Decisions in such political systems are made with a type of information processing that works in a linear framework of reference, but which is limited when finding optimal solutions in spaces of high complexity.

As we see it, one of the main problems with hierarchical arrangements for decisionmaking in complex societies is that the problems exceed the processing capacities of the tree topology (Mezza-Garcia, 2013). We know from biology that a system's dynamics depends greatly on its structure and vice versa, as nicely exemplified by Waddington's (2012) research on ontogenesis. Therefore, current political systems should be transforming toward operational architectures that more adequately reflect the complexity of the interacting systems from which they are composed and the systems of which they form a part and which they have to manage effectively (Mezza-Garcia and Maldonado, in prep.).

Conversely, heterarchical political organizations operate with decision-making dynamics whose computation is performed by an open system, i.e., that is in interaction with the world in various levels simultaneously in a distributed, parallel, diffuse, realtime and decentralized manner. Inputs and conditions can be modified during the computation, and external agents can therefore also interact with this process. Ideally, 'outputs' or decisions are produced bottom-up from local interactions, rather than only implemented in a top-down manner at the expense of the complexity of human social systems and their environments. This is a more interactive kind of computation (Goldin and Wegner, 2008), which can better describe the type of complex information processing taking place in social heterarchies (Mezza-Garcia, in prep.). Interactive computation is a form of so-called "hypercomputation" (Copeland and Proudfoot, 1999), i.e., computation that practically exceeds the computational power of the Turing machine and has a basis in systems of interaction and communication, such as the 
Internet and neural networks. Here we include heterarchical political systems in the class of systems that compute interactively.

Polities based on these more heterarchical principles have existed in the past, and many examples are known for North, Central and South America (e.g., Blanton and Fargher, 2012; DeMarrais, 2013; Feinman, 2001; Potter and King, 1995; Rogers, 1995). Decentralized pre-Hispanic societies in Colombia, such as the Muiscas, Tayronas, and Zenú, also deserve to be more closely investigated from this theoretical perspective. Our hope is that we can gain a comparative anthropological view, one that is at least partially formalized in terms of complex systems theory and computer models, and which can therefore be generalized to help us address the global challenges of the modern era. To be sure, there were already attempts to integrate systems theory and anthropology during the $60 \mathrm{~s}$ and $70 \mathrm{~s}$, mainly inspired by the widespread interest in cybernetics, with varying levels of success (e.g., Rodin et al., 1978; Salmon, 1978; Bateson, 1972; Turner, 1977). Famously, basic cybernetic principles of feedback have been applied to the archaeological study of Mesoamerica (Flannery, 1968).

But times have changed: systems theory has progressed since those early days into complexity theory and we can now take advantage of more powerful computer-based modeling. These ongoing developments provide new concepts and tools for archaeology that are just beginning to be applied (see, e.g., Kohler, 2012; Bentley and Maschner, 2008; Bintliff, 2004). In the following we introduce additional points of contact between these fields that deserve to be explored more systematically.

\section{Complex systems theory and self-optimization}

Complex systems theory is an area of mathematics that developed from chaos theory and dynamical systems theory, and which is being used in the sciences of life, mind, and sociality. Advances in game theory, network theory, and agent-based modeling are providing a treasure trove of insights that can be applied by anthropologists to better understand heterarchical social organization.

To begin with, it is crucial to highlight that complex systems theory offers a middle way that overcomes the traditional sociological dichotomy between agent-level and system-level explanations (Bintliff, 2004). When agents socially interact with each other they form a larger, nonlinearly coupled system that has emergent properties of its own that cannot be reduced to one (or the sum) of the individuals. Interacting agents are turned into coupled components of the social system they help to give rise to, and this transforms their internal dynamics in a way that can impose constraints and augment their abilities - an insight that can be demonstrated using agent-based modeling (Froese and Fuchs, 2012; Froese, Gershenson, and Rosenblueth, 2013). In essence, interacting agents are not the same kind of agents they would be if they were isolated. Taken 
together, this means that the agent-level and social-level are logically distinct, since each has its own specific properties, and yet they cannot be completely separated either, since they mutually condition their dynamics. This is a formal confirmation of the ideal of Giddens' (1984) theory of structuration, in which neither agency nor social structure are considered as primary.

This complex middle way whereby agent and society are neither one nor two opens up a new way of thinking about the origins of cooperation. It is often assumed that biological agents are by nature rationally selfish, and that therefore external circumstances have to somehow compel them to cooperate, for example by means of reciprocity or punishment. But complex systems theory reveals an alternative to rational choice theory that is more consistent with anthropology, namely that some social systems could transform the nature of the interacting agents, as components, to be more pro-social. For example, a simulation of the social interaction dynamics of pairs of agents has shown that they often persist in interacting even if this goes against their individual goals because it is difficult to escape from the self-sustaining dynamics of mutual entrainment (Froese and Di Paolo, 2010). This is a topic for future research, but it serves to highlight that assuming irredeemably selfish and rational agents as the basis for investigating the origins of cooperation adopts a worst-case and unrealistic scenario.

But even if we accept the worst-case scenario, there are still a number of ways of ensuring cooperation in the absence of centralized control. It is widely accepted in anthropology that a collective risk of failure enhances the prospects of large-scale group formation and cooperation, for example when having to defend against another group of attackers (Carballo, Roscoe, \& Feinman, 2014). And we know from game theoretic modeling that the specific kind of social organization plays an essential role, too. Specifically, it has been demonstrated that an increased risk of collective failure facilitates large-scale cooperation especially when the large-scale social system is composed of nested smaller groups (Santos and Pacheco, 2011). Indeed, such a scalefree or small-world organization, in which many individuals have relatively few social connections and few individuals have relatively many connections, is known to enhance cooperation in the absence of centralized control. This type of social organization can help to explain the emergence of cooperation in the absence of mechanisms based on individual reputation and punishment (Santos, Santos, \& Pacheco, 2008). More generally, game theoretic modeling has shown that social diversity enhances spontaneous cooperation (Santos, Pinheiro, Lenaerts, \& Pacheco, 2012). An important origin of such social heterogeneity is the ability of agents to freely shape their social relations, which points to another potential sociological principle worthy of empirical verification. And we do not need to assume pro-social intentions of the agents. In fact, game theory suggests that cooperation is also more easily maintained when agents are allowed to individually adjust their social ties as they wish, even if they do so in a completely self-interested manner (Santos, Pacheco, \& Lenaerts, 2006). 
These game theoretic insights can be supplemented by recent research in self-organizing and adaptive neural network systems. In particular, Watson and colleagues (2010) have shown that Hopfield networks can optimize their own interconnectivity by means of local optimizations performed by the interacting nodes. Specifically, it is already well known that constraint satisfaction problems can be encoded in the network connections, such that when the behaviors of the nodes converge onto an equilibrium, this set of behavioral states represents one solution to the target problem (Hopfield and Tank, 1985). However, the attractor landscape of a complex system typically has many more locally optimal solutions compared to globally optimal solutions, and a suboptimal solution will be found most of the time. Watson and colleagues discovered that this problem is avoided as long as nodes are allowed to slowly update their connections, e.g., by a form of Hebbian learning, and the set of behavioral states is occasionally randomized. The trick is that these changes to connections create a distributed associative memory, a well-known property of this kind of network, and the occasional behavior resets ensure that it is different equilibriums of the network that are being memorized. In this way the network starts to generalize over the solutions it has encountered and generalizes to even better configurations, in the sense that more constraints between nodes end up being satisfied. Finally, all nodes in the network implicitly cooperate with each other to solve the original problem, even without any centralized control and without any explicit knowledge of why this is so. The generality of this self-optimization mechanism means that it can be applied to the dynamics of social systems as well. People will try to minimize the constraints imposed by their social connections by changing their behavior and their connections, and similar results would be obtained if we assume they do so habitually (Davies et al., 2011), thus replacing neural Hebbian learning with Bourdieu's (1977) habitus. In the absence of such cooperation we find the so-called tragedy of the commons (Hardin, 1968), since the local, selfish optimizing activity of the agents (i.e., network nodes) will tend to prevent the emergence of better (more globally coordinated) solutions that depend on cooperation.

Watson and colleagues do not specify the nature of the periodic reset, but any disturbance to normal activity that is large enough to push the behavior of the social system into a different steady state will do the job. Froese, Gershenson, and Manzanilla (2014) have applied this model to study the possibility of self-organization in the ancient city of Teotihuacan, Central Mexico. They hypothesize that periodic large-scale rituals could have served as the process of behavioral 'randomization' because such ritual activity is more symbolic than the functional activity of everyday life; by definition its concrete expressions are arbitrary in that they largely depend on cultural conventions. Moreover, important rituals are typically characterized by a liminal stage in which the rules of everyday life are intentionally bracketed. The model therefore connects well with the work of Turner (1969), for whom "the essence of liminality is to 
be found in its release from normal constraints" (1977, p. 68). But other kinds of disruption of normal working activity are conceivable, as we will discuss below.

On the basis of this brief introduction to recent developments in complex systems theory, with a special focus on some of the various factors that can favor the spontaneous emergence of cooperation, we are now in a position to reflect about some potentially fitting examples of heterarchical social systems. We focus on three preHispanic societies in Colombia that usually receive less attention than the famous hierarchical states of the Americas, i.e. the Aztec, Maya and Incas.

\section{Heterarchical civilizations in pre-Hispanic Colombia}

Heterarchical communities are horizontally distributed networks of individuals that operate without any overarching centralized control structure (Crumley, 1995). Throughout history there have been various examples of such societies, especially during early prehistory (Rogers, 1995). However, many of these more egalitarian arrangements were eventually transformed into or replaced by more centralized societies, to the extent that there has been a tradition to equate social complexity with centralization of power and vertical differentiation (Flannery, 1972). Two large-scale agent-based models confirm this prediction for societies in both the Old World (Turchin et al., 2013) and New World (Kohler et al., 2012) by investigating the role of warfare and policing, respectively. Nevertheless, even though the exclusively hierarchical analysis strategy has been usefully applied to a variety of polities, it is not universally applicable. As we have mentioned, it is increasingly recognized that some complex societies were organized in a more "collective" manner (Blanton and Fargher, 2012). For example, a heterogeneous perspective has been productively applied to gain a better understanding of the social organization of many complex polities in Mesoamerica (e.g., Blanton et al., 1996; Carballo, et al., 2014; Feinman, 2001; Manzanilla, 2007; Potter and King, 1995). We suggest that this heterogeneous perspective should be extended to include some of the pre-Hispanic polities in Colombia, and especially by taking the latest insights from complex systems theory into account.

The Tayrona were a loosely integrated group of chiefdoms in the Sierra Nevada de Santa Marta in the northwestern coast of Colombia (Giraldo Pélaez, 2009). Although there is archaeological evidence for some social differentiation on the basis of differences in burials, the Tayrona social organization does not fit with the usual expectations. Buildings in their cities were connected by a maze of pathways with some central nodes but without any clear principal avenues, and the more important buildings were not physically separated from the rest of the city (Giraldo Pélaez, forthcoming). It is possible that we are dealing with a small-world or scale-free architecture of social relations, which has been shown to be conducive for the spontaneous emergence of cooperation (although it can also be taken as an indication of social hierarchy, see 
Brughmans, 2013). Moreover, large ritual plazas have been excavated, but there are no indications of exclusionary religious practices or of competitive feasting. Instead these places seem to have been used for community rituals involving tobacco and Chicha (corn juice beer). Such periodic ritualized interruptions to normal working life, as shown in Figure 1, may lead to social self-optimization, as Froese, Gershenson, and Manzanilla (2014) have proposed for the case of ancient Teotihuacan, Mexico.

Anthropologists have observed that the Kogi, an indigenous people that descended from the Tayrona, tend to live in an even more decentralized manner than their ancestors (Caicedo, 1986). While the reasons for this change toward a more collective social organization are still relatively unknown, we hypothesize, following insights from the game theoretic models discussed above, that the significantly increased risk of collective failure brought on by the disasters of the Spanish conquest was a crucial factor - disasters whose catastrophic effects have been extensively documented (Giraldo Pélaez, 2000, 2012).

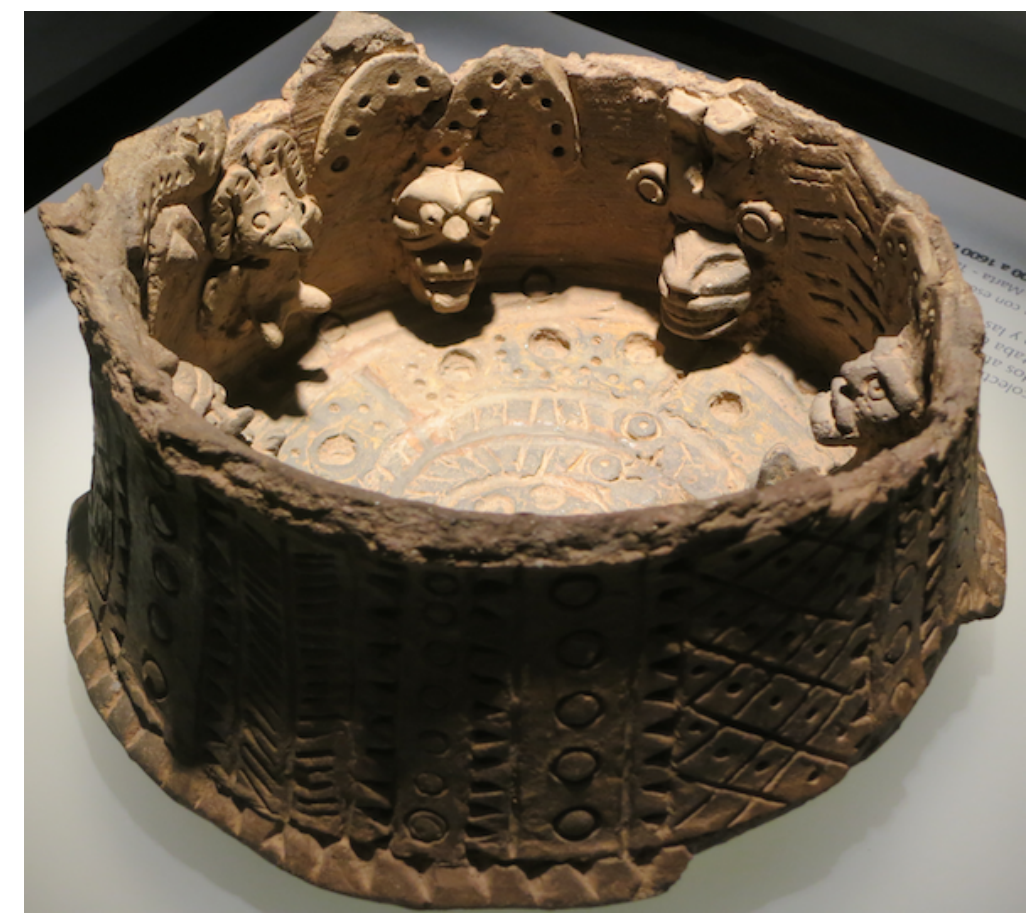

Figure 1. Vessel produced by the Tayrona in the Sierra Nevada de Santa Marta between 900 and 1600 AD showing a ritual scene. The accompanying text reads: "An intense communion with the universe and divinities was experienced at collective ceremonies, due to the ancient dances, the complicated and sumptuous costumes, and the moving music." We thank the Museo de Oro, and in particular Eduardo Londoño Laverde, for the permission to take and reproduce this photo. 
Another noteworthy example of a past culture in Colombia without any clear center of power is the Zenú. They converted an extensive territory into use for agriculture by creating a huge network of dams and canals, which helped to spread the impact of annual inundations during the rainy season and to retain moisture during the dry period (Montejo Gaitán, 2013). People lived on artificially raised platforms. Due to the classic hydraulic hypothesis in anthropology, it might be expected that the Zenú were a centrally organized civilization with rulers whose power was based on the control of water. But this does not seem to fit the facts (Rojas, 2008). No large palaces have been uncovered and while grave goods show signs of luxury, this was distributed across the population. Not much is known about how the Zenú arranged the construction and management of this extensive water system without centralized control. We hypothesize that the drastic effects of seasonal changes, which imposed completely different life styles depending on the level of water, could have served as the mechanism of disruption that Watson and colleagues found to facilitate self-optimization.

Finally, it is of interest to consider the social organization of the Muiscas who lived in the center of Colombia. Their society was organized into what the Spanish described as a confederation, without any single center of control (Langebaek et al., 2011). There were settlements of many different sizes and in a variety of climatic zones, which were interconnected by an extensive network of trails. Interestingly, a diversity of social connectivity facilitates the maintenance of cooperation, as shown by game theory. It is also known that many powerful mind altering substances were used, but these seem to have been exclusive to religious professionals. Nevertheless, we suspect that there might have also been more communal rituals involving altered states of consciousness, since these events, following the model by Watson et al., would have served as the behavior reset mechanism leading to spontaneous self-optimization of relations in such a heterarchically-organized system. We further hypothesize that rituals involving human sacrifice might have provided the periodic social disruption needed for selfoptimization. A significant part of the community assembled for these public rituals and they also temporarily changed the behavior of the people from their ordinary activities (Sotomayor, 1990), thereby resetting the whole social system.

More generally, we hypothesize that there was a correlation between the amount of social flexibility in changing status and relationships and the extent of heterarchical organization. This is because game theory has demonstrated that cooperation without central control is facilitated when agents are allowed to quickly adjust their social relations. It remains to be seen if our predictions are verified by future network- and game-theoretical approaches in archaeological research. The flexibility of these approaches make them fertile tools for the study of the nonlinear social interactions that are present in political organizations that do not process information $\grave{a}$ la Turing. 


\section{Final remarks and future work}

The increasing interconnectedness of our social systems worldwide implies that sociopolitical problems have global implications (Gershenson et al., 2014). The complexity of solutions to global warming and climate change, food scarcity, energy supply, water consumption, population growth, loss of biodiversity, epidemics and pandemics, among others, require cooperative, decentralized, multilevel and distributed solutions for which Turing machine computational architectures of decision-making are inadequate. In contrast, complex systems approaches can provide optimal solutions by using the complexity of our social systems to their own benefit (Axelrod and Cohen, 2000). Translated into politics, this would be equivalent to systems of decision and regime structures that are sufficiently robust to maintain internal coherence and yet are flexible enough to rapidly adapt to changes in time. History provides effective examples of political structures that have operated in this non-centralized way, to which we can turn for inspiration about the possibilities of social heterarchy. Archaeology has long focused on ancient centralized elite hierarchies at the expense of other forms of social organization, but this is beginning to change (Kienlin, 2012). We agree that what also needs to be investigated are social and political systems with a strong tendency to selforganize and self-optimize, that is, systems that exhibit precisely the kinds of social dynamics that are more readily expressed in non-hierarchical political regimes. Of course, it should go without saying that heterarchical social systems are not infallible either, as the collapse of the pre-Hispanic polities in Colombia clearly demonstrates. So we will also need to further study their own particular weaknesses compared to those of hierarchical systems.

In conclusion, we propose that computational modeling approaches to anthropology and sociology are potentially synergetic workspaces. Modeling and simulation, for example, can help archaeologists to conduct hypothetical studies on systems that no longer exist. Similarly, sociologists, given that the systems they study - individuals within human societies - are complex systems, can also resort to these expressive and formal computational tools to find out what could be the optimal social configurations for their intricate and convoluted problems. Conversely, complex systems researchers can test some of their latest theories of self-organization by applying them to the archaeological study of unusual social systems that happen to be more clearly characterized by nonlinear information processing and lack of centralized political control.

Our hope is that by formally studying the various kinds of processes that allowed ancient heterarchical communities to adapt successfully over centuries, and by determining what were the causes of their eventual downfall, we can gain new insights about how to better organize and manage our own societies. Since the contemporary world is increasingly composed of complex networks of all sorts, especially those 
involving decentralized decision-making, learning how to better operate in these contexts is crucial for adequately addressing the global problems that we now face. Moreover, a crucial advantage of computational approaches is that we can make tools that do not require that we use the world as a laboratory, thereby avoiding the problem of having to impose decisions upon it that have not been tested before.

Acknowledgments. T.F. was partially funded by the Convocatoria de Proyectos de Desarrollo Científico para Atender Problemas Nacionales 2013, "Guiando Comportamientos para Mejorar la Movilidad Urbana" (CONACYT 212802). We thank Santiago Giraldo Pélaez from the Global Heritage Fund and one anonymous reviewer for their helpful comments.

\section{References}

Axelrod, R., \& Cohen, M. (2000). Harnessing complexity: Organizational implications of a scientific frontier. Basic books.

Bateson, G. (1972). Steps to an Ecology of Mind: Collected Essays in Anthropology, Psychiatry, Evolution, and Epistemology. San Francisco, CA: Chandler Pub.

Bentley, R. A., \& Maschner, H. D. G. (2008). Complexity theory. In R. A. Bentley, H. D. G. Maschner \& C. Chippendale (Eds.), Handbook of Archaeological Theories (pp. 245-270). Lanham, MD: AltaMira Press.

Bintliff, J. (2004). Time, structure, and agency: The Annales, emergent complexity, and archaeology. In J. Bintliff (Ed.), A Companion for Archaeology (pp. 174-194). Malden, MA: Blackwell Publishing Ltd.

Blanton, R. E., \& Fargher, L. F. (2012). Neighborhoods and the civic constitution of premodern cities as seen from the perspective of collective action. In M. C. Arnauld, L. R. Manzanilla, \& M. E. Smith (Eds.), The Neighborhood as a Social and Spatial Unit in Mesoamerican Cities (pp. 26-52). Tucson, AZ: The University of Arizona Press.

Blanton, R. E., Feinman, G. M., Kowalewski, S. A., \& Peregrine, P. N. (1996). A dualprocessual theory for the evolution of Mesoamerican civilization. Current Anthropology, $37(1), 1-14$.

Bourdieu, P. (1977). Outline of a Theory of Practice. Cambridge, UK: Cambridge University Press.

Brughmans, T. (2013). Thinking through networks: A review of formal network methods in archaeology. Journal of Archaeological Method and Theory, 20, 623-662.

Caicedo, A. O. (1986). De los Taironas a los Kogi: Una interpretación del cambio cultural. Boletín del Museo del Oro, 17, 32-43. 
Carballo, D. M., Roscoe, P., \& Feinman, G. M. (2014). Cooperation and collective action in the cultural evolution of complex societies. Journal of Archaeological Method and Theory, 21, 98-133.

Copeland, B., \& Proudfoot, D. (1999). Alan Turing's Forgotten Ideas in Computer Science. Scientific American, 280, 76-81.

Crumley, C. L. (1995). Heterarchy and the analysis of complex societies. Archeological Papers of the American Anthropological Association, 6, 1-5.

Davies, A. P., Watson, R. A., Mills, R., Buckley, C. L., \& Noble, J. (2011). "If you can't be with the one you love, love the one you're with": How individual habituation of agent interactions improves global utility. Artificial Life, 17(3), 167-182.

DeMarrais, E. (2013). Understanding heterarchy: Crafting and social projects in preHispanic Northwest Argentina. Cambridge Archaeological Journal, 23(3), 345-362.

Eberbach, E., Goldin, D., \& Wegner, P. (2004). Turing's ideas and models of computation. In C. Teuscher (Ed.), Alan Turing: Life and Legacy of a Great Thinker (pp. 159-194). Berlin, Germany: Springer.

Feinman, G. M. (2001). Mesoamerican political complexity: The corporate-network dimension. In J. Haas (Ed.), From Leaders to Rulers (pp. 151-175). New York, NY: Kluwer Academic.

Fernández, N., Maldonado, C., \& Gershenson, C. (2014). Information measures of complexity, emergence, self-organization, homeostasis, and autopoiesis. In M. Prokopenko (Ed.), Guided Self-Organization: Inception (pp. 19-51). Berlin: Springer.

Flannery, K. V. (1968). Archaeological systems theory and early Mesoamerica. In B. Meggers (Ed.), Anthropological Archaeology in the Americas (pp. 67-87). Washington, DC: Anthropological Society of Washington.

Flannery, K. V. (1972). The cultural evolution of civilizations. Annual Review of Ecology and Systematics, 3, 399-426.

Froese, T., \& Di Paolo, E. A. (2010). Modelling social interaction as perceptual crossing: An investigation into the dynamics of the interaction process. Connection Science, 22(1), 4368.

Froese, T., \& Fuchs, T. (2012). The extended body: A case study in the neurophenomenology of social interaction. Phenomenology and the Cognitive Sciences, 11(2), 205235.

Froese, T., Gershenson, C., \& Manzanilla, L. R. (2014). Can government be self-organized? A mathematical model of the collective social organization of ancient Teotihuacan, Central Mexico. PLoS ONE 9 (10): e109966. Doi: 10.1371/journal.phone.0109966

Froese, T., Gershenson, C., \& Rosenblueth, D. A. (2013). The dynamically extended mind: A minimal modeling case study. In 2013 IEEE Congress on Evolutionary Computation (pp. 1419-1426). IEEE Press. 
Gershenson, C. (2013). Information and computation. In P. Michelucci (Ed.), Handbook of Human Computation (pp. 61-69). New York: Springer.

Gershenson, C., Csermely, P., Érdi, P., Knyazeva, H., \& Lazlo, A. (2014). The present and future of cybernetics and systems research. Systema, 1(3), 4-13.

Gershenson, C., \& Fernández, N. (2012). Complexity and information: Measuring emergence, self-organization, and homeostasis at multiple scales. Complexity, 18(2), 2944.

Giddens, A. (1984). The Constitution of Society: Outline of the Theory of Structuration. Cambridge, UK: Polity Press.

Giraldo Pélaez, S. (forthcoming). Nuevas aproximaciones al urbanismo Tairona. In Santa Marta y el Magdalena Grande de los Tiempos Precolombianos al Siglo XX. Santa Marta: Universidad del Magdalena.

Giraldo Pélaez, S. (2012). Cultura kogi y Ciudad Perdida. In C. Duque Duque (Ed.), Lenguaje Creativo de las Etnias Indigenas en Colombia (pp. 454-458). Suramericana Editores: Medellin, Colombia.

Giraldo Pélaez, S. (2009). Parque Arqueológico Teyuna-Ciudad Pérdida. Guía para visitantes. Edición bilingüe español-inglés. (Textos y Traducción). Bogotá: ICANHGlobal Heritage Fund.

Giraldo Pélaez, S. (2000). Del Rioja y otras cosas de los caciques: Patrones de intercambio Tairona en el Siglo XVI. Revista de Arqueologia del Área Intermedia, 2.

Goldin, D., \& Wegner, P. (2008). The interactive nature of computing: Refuting the strong Church-Turing Thesis. Minds and Machines, 18, 17-38.

Hardin, G. (1968). The tragedy of the commons. Science, 162, 1243-1248.

Hopfield, J. J., \& Tank, D. W. (1985). "Neural" computation of decisions in optimization problems. Biological Cybernetics, 52, 141-152.

Kienlin, T. L. (2012). Beyond elites: An introduction. In T. L. Kienlin \& A. Zimmermann (Eds.), Beyond Elites: Alternatives to Hierarchical Systems in Modelling Social Formations (pp. 15-32). Bonn, Germany: Dr. R. Habelt GMBH.

Kohler, T. A. (2012). Complex systems and archaeology. In I. Hodder (Ed.), Archaeological Theory Today. Second Edition (pp. 93-123). Cambridge, UK: Polity Press.

Kohler, T. A., et al. (2012). Modelling prehispanic Pueblo societies in their ecosystems. Ecological Modelling, 241, 30-41.

Langebaek, C. H., Bernal, M., Aristizabal, L., Corcione, M. A., \& Rojas, C. S. (2011). Condiciones de vida y jerarquías sociales en el norte de Suramérica: El caso de la población Muisca en Tibanica, Soacha. Indiana, 28, 15-34.

Manzanilla, L. R. (2007). State formation in the New World. In G. M. Feinman, \& T. D. Price (Eds.), Archaeology at the Millennium: A Sourcebook (pp. 381-413). New York, NY: Springer US. 
Mezza-Garcia, N. (2013). Self-organized sociopolitical interactions as the best way to achieve organized patterns in human social systems: Going beyond the top-down control of classical political regimes. Unpublished Bachelor Thesis. Bogota, Colombia: Universidad del Rosario.

Mezza-Garcia, N. (in preparation). The non-algorithmic beauty of politics: Political systems with interactive information processing.

Mezza-Garcia, N., \& Maldonado, C. E. (in preparation). Crítica al control jerárquico de los regímenes políticos clásicos: Complejidad y topología.

Montejo Gaitán, F. (2013). Estudio de la modificación antrópica prehispánica en humedales. Análisis espacial integrado a un sistema de información geográfica (avances de investigación). Boletín de Arqueología PUCP, 24, 51-93.

Potter, D. R., \& King, E. M. (1995). A heterarchical approach to lowland Maya socioeconomies. Archeological Papers of the American Anthropological Association, 6, $17-32$.

Rodin, M., Michaelson, K., \& Britan, G. M. (1978). Systems theory in anthropology. Current Anthropology, 19(4), 747-762.

Rogers, R. J. (1995). Tribes as heterarchy: A case study from the prehistoric southeastern United States. Archeological Papers of the American Anthropological Association, 6, 716.

Rojas, S. (2008). Acerca de la complejidad social y sus referentes en el escenario del bajo río San Jorge (Caribe colombiano). Boletin de Antropología -Universidad de Antioquia, 22(39).

Salmon, M. H. (1978). What can systems theory do for archaeology? American Antiquity, 43(2), 174-183.

Santos, F. C., \& Pacheco, J. M. (2011). Risk of collective failure provides an escape from the tragedy of the commons. Proceedings of the National Academy of Sciences of the USA, 108(26), 10421-10425.

Santos, F. C., Pacheco, J. M., \& Lenaerts, T. (2006). Cooperation prevails when individuals adjust their social ties. PLoS Computational Biology, 2(10), e140. doi: 10.1371/journal.pcbi.0020140

Santos, F. C., Pinheiro, F. L., Lenaerts, T., \& Pacheco, J. M. (2012). The role of diversity in the evolution of cooperation. Journal of Theoretical Biology, 299, 88-96.

Santos, F. C., Santos, M. D., \& Pacheco, J. M. (2008). Social diversity promotes the emergence of cooperation in public goods games. Nature, 454, 213-216.

Sotomayor, M. L. (1989-1990). Dos sacrificios humanos entre los muiscas. Revista Colombiana de Antropología, 27, 37-52.

Turchin, P., Currie, T. E., Turner, E. A. L., Gavrilets, S. (2013). War, space, and the evolution of Old World complex societies. Proceedings of the National Academy of Sciences of the USA, 110(41), 16384-16389. 
Turner, V. (1969). The Ritual Process: Structure and Anti-Structure. Piscataway, NJ: Aldine Transaction.

Turner, V. (1977). Process, system, and symbol: A new anthropological synthesis. Daedalus, 106: $61-80$.

Waddington, C. H. (2012). The Epigenotype. International Journal of Epidemiology, 41(1), 10-13.

Watson, R. A., Buckley, C. L., \& Mills, R. (2010). Optimization in "self-modeling" complex adaptive systems. Complexity, 16(5), 17-26. 